\title{
Depressive symptoms, sexual activity, and substance use among adolescents in Kampala, Uganda
}

\author{
Michael B Henry ${ }^{1}$, Sabrina Bakeera-Kitaka ${ }^{2,3}$, Kizza Lubega ${ }^{3}$, Sara A. Snyder ${ }^{4,5}$, \\ Philip LaRussa ${ }^{1}$, Betsy Pfeffer ${ }^{1}$
}

1. Columbia University, Department of Pediatrics, College of Physicians and Surgeons, New York, USA.

2. Makerere University College of Health Sciences, Department of Paediatrics and Child health, Kampala, Uganda.

3. Mulago Hospital, Makerere/Mulago Columbia Adolescent Health Clinic (MMCAH), Kampala, Uganda.

4. Columbia University, Mailman School of Public Health, New York, USA.

5. Long Island University, Department of Clinical Psychology, New York, USA.

\section{Author emails:}

mhenry12@gmail.com, sabrinakitaka@yahoo.co.uk, Allncc@yahoo.com, Sara.A.Snyder@caa.columbia.edu, plarussa@columbia.edu,bp35@columbia.edu

\begin{abstract}
:
Background: Adolescents experience high rates of depression, initiation of sexual activity, and substance use.

Objectives: To better understand the demographics of adolescents presenting to an adolescent clinic in Uganda, and to elucidate which factors are associated with depressive symptoms, sexual initiation, and substance use.

Methods: A retrospective review was performed on intake forms obtained during interviews with adolescents presenting to the Makerere/Mulago Columbia Adolescent Health Clinic (MMCAH) in Kampala, Uganda.

Results: Depressive symptoms in adolescents were correlated with having a chronic illness $(\mathrm{p}=.026)$, and reported poor quality of home life $(p<.001)$. Initiation of sexual activity was also correlated with chronic illness $(p=.008)$ and poor quality of home life $(\mathrm{p}=.006)$. Substance use was correlated with maternal death $(\mathrm{p}=.041)$, chronic illness $(\mathrm{p}=.038)$, and substance use among family members $(\mathrm{p}<.001)$ and friends $(\mathrm{p}<.001)$.

Conclusions: Knowing the aforementioned risk factors can help us better understand the needs of adolescents presenting to MMCAH, and allows us to develop targeted interventions aimed at decreasing health risks in Kampala's adolescent population.

Keywords:

DOI: https://dx.doi.org/10.4314/ahs.v19i2.12

Cite as: Henry MB, Kitaka SB, Lubega K, Snyder SA, LaRussa P, Pfeffer B. Depressive symptoms, sexual activity, and substance use among adolescents in Kampala, Uganda. Afri Health Sci.2019;19(2): 1888-1896. https:// dx.doi.org/10.4314/abs.v19i2.12
\end{abstract}

\section{Introduction}

Many Ugandan families have traditionally encouraged their youth to be socially conservative; nevertheless, recent estimates suggest that nearly one-third of Ugandan adolescents had sex ${ }^{1}$, and two-thirds tried drugs or

\section{Corresponding author: \\ Michael Henry, \\ Columbia University, \\ Department of Pediatrics, \\ College of Physicians and Surgeons, \\ New York, USA. \\ Tel: +1 (717) 798-6275 \\ Email: Mhenry12@gmail.com}

alcohol during their adolescence ${ }^{2}$. Depression also has a high burden on Ugandan adolescents, with almost 20\% reporting having significant symptoms of depression ${ }^{3}$. Poverty, low levels of education, and limited access to health care among this population may be associated with these increased risks ${ }^{1,3}$. There is currently a lack of resources to support Ugandan adolescents navigating these challenging years.

Adolescence is defined by the World Health Organization (WHO) as the critical development period between childhood and adulthood (ages 10-19) ${ }^{4}$. It is also a period of increased risk taking behaviors and psychological stresses which can lead to mortality and morbidity ${ }^{4,5,6}$. Globally, there is a need to support adolescents so that they grow into healthy and productive adults.

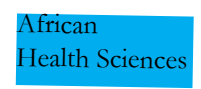

(C) 2019 Henry et al. Licensee African Health Sciences. This is an Open Access article distributed under the terms of the Creative commons Attribution License (https://creativecommons.org/licenses/BY/4.0), which permits unrestricted use, distribution, and reproduction in any medium, provided the original work is properly cited. 
Preventative counseling could make a difference in the adolescent population, both globally and specifically in Uganda, to address depression, sexual activity, and substance use and their associated morbidities ${ }^{7}$. Depressive disorders are a leading cause of morbidity globally, and are associated with increased risk of suicide and heart disease $^{8}$; suicide is a top cause of death in adolescents ${ }^{9}$. Sexual activity can potentially lead to HIV, other sexually transmitted infections, and unanticipated pregnancies, all of which are present at high levels in sub-Saharan Afri$\mathrm{ca}^{10,11}$. High rates of substance use ${ }^{12}$ can lead to serious consequences in regards to physical and mental health, as well as psychosocial well-being ${ }^{13}$. This paper prescribes to the WHO convention of "substances" being defined as alcohol or illegal drug use; any mention of tobacco use will be independent of this definition ${ }^{12}$.

The Makerere/Mulago Columbia Adolescent Health Clinic (MMCAH) in Kampala, Uganda is a comprehensive adolescent health care clinic that started in May 2013. As of July 2015, the clinic had provided care to over 700 patients. The MMCAH providers offer health assessments, reproductive services including contraception, and sexually transmitted infection management, chronic disease management, and substance use and psychological counseling ${ }^{14}$.

To better ascertain the needs of the Kampala adolescent population, we conducted a review of MMCAH's patient intake forms collected at presentation for routine care between May 2013-July 2015. Our aims were twofold: 1) to better understand the needs of adolescents presenting for care, allowing the MMCAH to optimize its services, and grow into a model adolescent clinic; and 2) to understand factors correlated to health outcomes by drawing connections between demographic data, and risk of depressive symptoms, sexual activity, and substance use.

\section{Methods}

After obtaining Institutional Review Board approval from Columbia University Medical Center and Makerere College of Health Sciences, data were abstracted from MMCAH's baseline intake form. The 95-item intake form includes questions based on the "HEADDSS" Model for adolescent preventive health care (Home/health, Education/employment, Activities, Drugs, Depression, Safety, Sexuality $)^{7}$. Clinic staff or physicians completed the in- take form during patients' initial visit, and subsequently used it to guide patient interactions. Of the 702 patients presenting to the clinic between May 2013 and July 2015, some 558 intake forms were completed, 514 of which met the study age inclusion criteria.

Data was extracted from the intake forms and entered into EpiData 3.1 to function as an electronic record of intake forms for the MMCAH. For the purposes of this study, de-identifed data were exported from EpiData into Microsoft Excel.

Data was analyzed based on responses to questions regarding depression, sexual activity, and substance use; all questions were posed in a dichotomous manner ("yes" or “no"). Analyses beyond dichotomous response options were not possible due to the low response rates to follow-up sexual activity and substance use questions, the majority of which were left blank.

- Depression-related questions ("yes" to either counted as a positive history of depression):

o "Have you ever felt like hurting yourself or suicide?"

o "In the past, have you ever felt so sad or hopeless that you stopped doing some of your usual activities?"

- Sexual activity: "Have you ever had sex?"

- Substance use ("yes" to either counted as positive history of substance use):

o "Have you had a drink of alcohol, other than a few sips?"

o "Have you ever used illegal drugs?"

Factors assessed for correlations with self-reported history of depressive symptoms, sexual activity, and substance use included: gender, residence (within Kampala city vs outside), parents alive or dead, presence of a known chronic illness, subjective judgment on quality of home life, religious activity, being currently employed or in school, and self-knowledge of HIV status. For substance use, we also assessed the connection to drug or alcohol use among friends, and drug or alcohol problems among family members. Chronic diseases listed on the form included: asthma, diabetes, cancer, sickle cell disease, HIV, epilepsy, tuberculosis, sexually transmitted infections, and "other" or "unknown". When asked to elaborate on "other", most respondents wrote "none", or generally minor conditions such as "allergies". We therefore analyzed data dichotomously with patients either having one of the listed chronic illnesses, or not. 
Pearson correlations were run using SPSS 24 with significant $\mathrm{p}$-value $<0.05$. Records in which any field was missing for a given analysis were excluded (e.g. if a patient denied using drugs but did not respond to history of alcohol use, they were left out of analysis for history of substance use). Charts and graphs were created using Microsoft Excel.

\section{Results}

Our predominately female (72.4\%) sample was comprised of 514 adolescents 10-19 (mean=16) years of age. The majority reported being religious (93\%). Three-quarters $(73.9 \%)$ of patients lived in Kampala, most were in school $(84.1 \%)$, and a minority were employed $(7.3 \%)$. The majority still had a living mother $(86.2 \%)$ and father $(72.6 \%)$, and reported a good quality of home life $(81.5 \%)$. A minority reported having a known chronic disease (11.9\%) and several reported having HIV (2.3\%). See Table 1 for a complete list of the sample's demographics.

Table 1. Demographic characteristics and prevalence of depressive symptoms, sexual initiation, and substance use among the 514 adolescents aged 10-19 years old

\begin{tabular}{|l|l|l|l|}
\hline Gender & 372 female $(72.4 \%)$ & 142 male $(27.6 \%)$ & \\
\hline Residence & 380 Kampala $(73.9 \%)$ & $\begin{array}{l}126 \text { outside Kampala } \\
(24.5 \%)\end{array}$ & 8 no response $(1.6 \%)$ \\
\hline Mother alive & 443 yes $(86.2 \%)$ & 63 no $(12.3 \%)$ & 8 no response $(1.6 \%)$ \\
\hline Father alive & 373 yes $(72.6 \%)$ & 124 no $(24.1 \%)$ & 17 no response $(3.3 \%)$ \\
\hline Known chronic disease & 61 yes $(11.9 \%)$ & 453 no $(88.1 \%)$ & \\
\hline Subjective home life & 419 good $(81.5 \%)$ & 85 not good $(16.5 \%)$ & 10 no response $(1.9 \%)$ \\
\hline Religion & 478 yes $(93.0 \%)$ & 14 no $(2.7 \%)$ & 22 no response $(4.3 \%)$ \\
\hline $\begin{array}{l}\text { Activities } \\
\text { (attends school or work) }\end{array}$ & 442 yes $(86.0 \%)$ & 51 no $(9.9 \%)$ & 21 no response $(4.1 \%)$ \\
\hline Known HIV & 12 positive $(2.3 \%)$ & 222 negative $(43.2 \%)$ & 280 no response $(54.5 \%)$ \\
\hline $\begin{array}{l}\text { Alcohol or drug use } \\
\text { (among friends) }\end{array}$ & 85 yes $(16.5 \%)$ & 416 no $(80.1 \%)$ & 13 no response $(2.5 \%)$ \\
\hline $\begin{array}{l}\text { Alcohol or drug problem } \\
\text { (among family) }\end{array}$ & 99 yes $(19.3 \%)$ & 381 no $(74.1 \%)$ & 34 no response $(6.6 \%)$ \\
\hline
\end{tabular}

\begin{tabular}{|l|l|l|l|}
\hline Sad/hopeless feelings & 159 yes $(30.9 \%)$ & 289 no $(56.2 \%)$ & 66 no response $(12.8 \%)$ \\
\hline Self-harm thought & 83 yes $(16.1 \%)$ & 399 no $(77.6 \%)$ & 32 no response $(6.2 \%)$ \\
\hline $\begin{array}{l}\text { Either depressive } \\
\text { symptom }\end{array}$ & 174 yes $(33.9 \%)$ & 270 no $(52.5 \%)$ & 70 no response $(13.6 \%)$ \\
\hline
\end{tabular}

\begin{tabular}{|l|l|l|l|}
\hline Sexual initiation & 85 yes $(16.5 \%)$ & 168 no $(32.7 \%)$ & 261 no response (50.8\%) \\
\hline
\end{tabular}

\begin{tabular}{|l|l|l|l|}
\hline Alcohol use & 78 yes $(15.2 \%)$ & 412 no $(80.2 \%)$ & 24 no response $(4.7 \%)$ \\
\hline Tobacco use & 20 yes $(3.9 \%)$ & 482 no $(93.8 \%)$ & 12 no response $(2.3 \%)$ \\
\hline Drug use & 11 yes $(2.1 \%)$ & 481 no $(93.6 \%)$ & 22 no response $(4.3 \%)$ \\
\hline Alc or drug use & 80 yes $(15.6 \%)$ & 390 no $(75.9 \%)$ & 44 no response $(8.6 \%)$ \\
\hline
\end{tabular}


A minority of patients self-reported a history of depressive symptoms $(33.9 \%)$, sexual activity $(16.5 \%)$, and substance use of either alcohol or drugs (17.3\%); our three main factors of interest.

\section{Depressive symptoms}

Of the 514 adolescents, $30.9 \%$ reported feeling sad, or hopeless, and $16.1 \%$ reported having thoughts of selfharm; $33.9 \%$ of patients reported at least one of these symptoms, and were therefore considered positive for presence of depressive symptoms. On $13.6 \%$ of intake forms we were unable to conclude whether one of these symptoms had been present, as one or both of the questions remained unanswered. Factors signficiantly correlated with depressive sympoms include the presence of a chronic disease $(p=.026)$ and a poor quality of home life $(p<0.001)$. Female gender was close to statistical significance $(\mathrm{p}=0.063)$. Depressive symptom prevalence appears higher among those belonging to a religion compared to those who do not, but the small numbers of non-religious adolescents limited the power to detect a significant difference (Table 2 and Figure 1).

Table 2. Factors assessed on survey in relation to reported history of depressive symptoms, sexual activity, or substance use, and associated $p$-values.

\begin{tabular}{|l|l|r|r|r|}
\hline Demographic factors & Possible responses & $\begin{array}{r}\text { Depressive } \\
\text { Symptoms }\end{array}$ & $\begin{array}{r}\text { Sexual } \\
\text { Initiation }\end{array}$ & $\begin{array}{r}\text { Substance } \\
\text { use }\end{array}$ \\
\hline Gender & Male, Female & 0.063 & 0.444 & 0.344 \\
\hline Residence & Kampala, Outside Kampala & 0.787 & 0.182 & 0.553 \\
\hline Mother & Alive, Dead & 0.645 & 0.145 & $* * 0.041$ \\
\hline Father & Alive, Dead & 0.522 & 0.306 & 0.550 \\
\hline Chronic disease & Yes (listed), No/Other/Unknown & $* * 0.026$ & $* * 0.008$ & $* * 0.038$ \\
\hline Home & Good, Not & $* *<0.001$ & $* * 0.006$ & 0.659 \\
\hline Religion & Yes, No & 0.098 & 0.222 & 0.846 \\
\hline Activities & Employed or in school, Not & 0.189 & 0.495 & 0.439 \\
\hline Known HIV & Positive, Negative & 0.806 & 0.691 & 0.197 \\
\hline Friends substance use & Friend either drink/do drugs, No & & & $* *<0.001$ \\
\hline & $\begin{array}{l}\text { Family member has either } \\
\text { alcohol/drug problem, No }\end{array}$ & & & $* * 0.001$ \\
\hline
\end{tabular}

$* *$ significant at $\mathrm{p}=0.05$

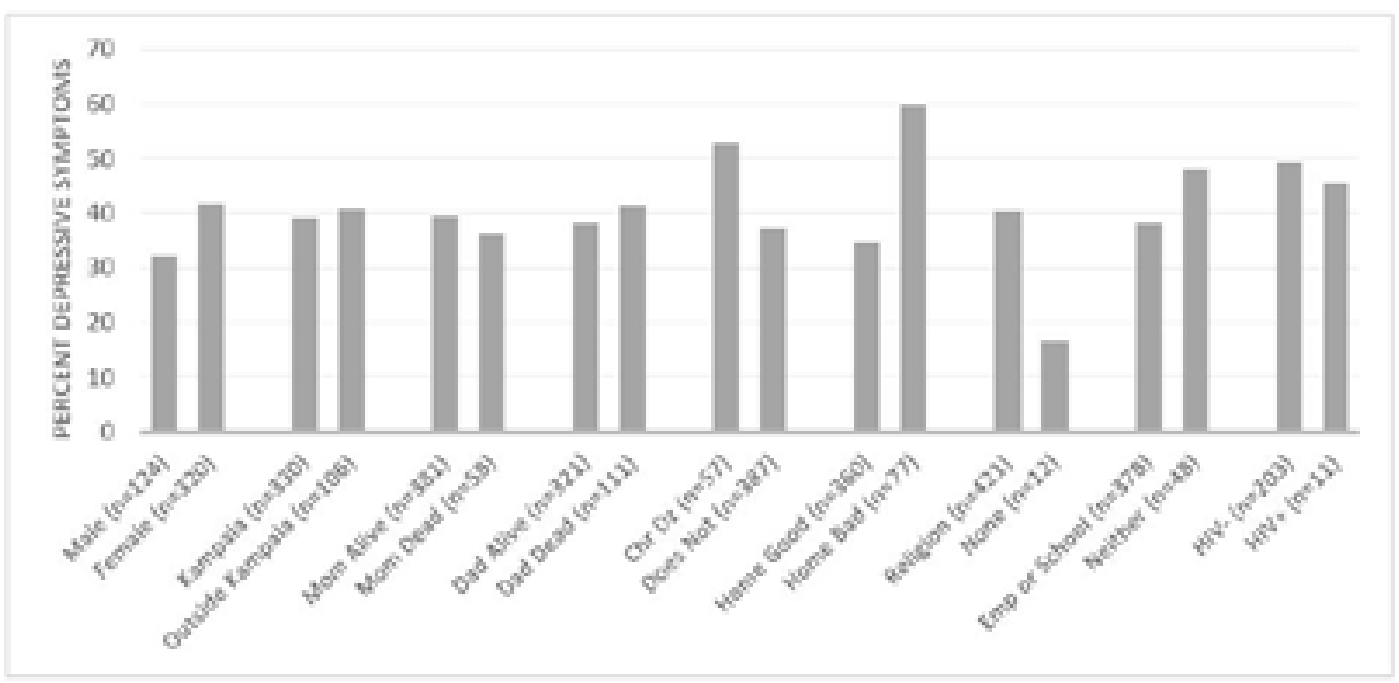

Figure 1. Percentage of Respondents with History of Depressive Symptoms 


\section{Sexual activity}

This question was answered by $49.2 \%$ of the participants, and of these only $16.5 \%$ reported having been sexually active. Adolescents who had a chronic illness were more likely to be sexually active $(\mathrm{p}=0.008)$, as were adolescents who reported poor quality home life $(p=0.006)$. None of the non-religious patients reported sexual activity, but only three individuals in this group answered the question $(p=0.222)$. See Table 2 and Figure 2.

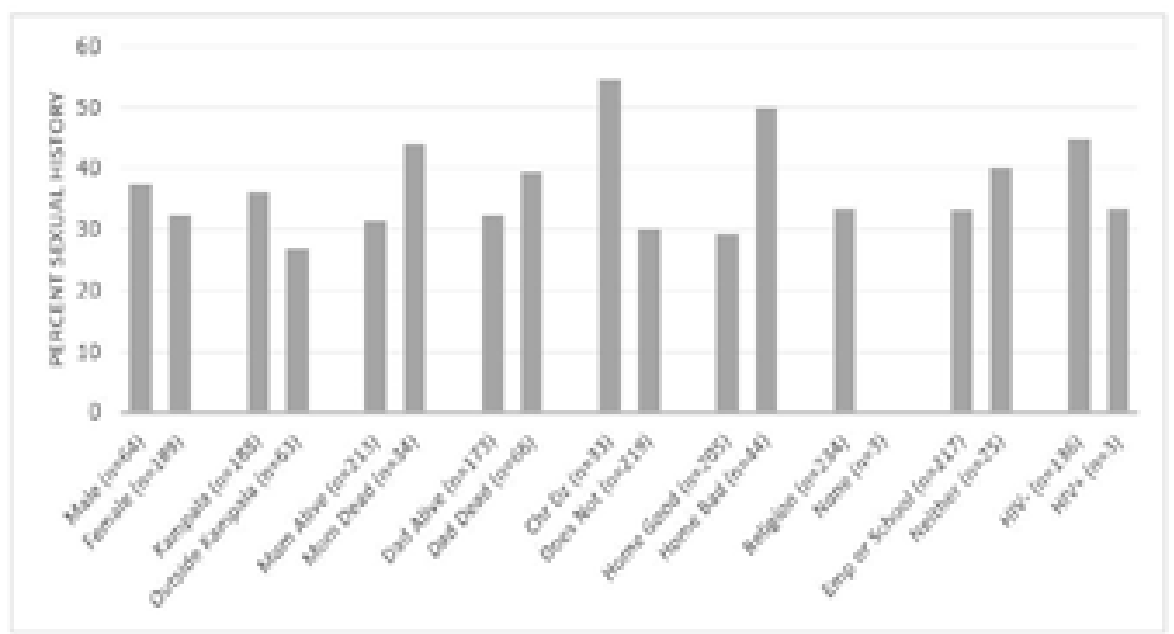

Figure 2. Percentage of respondents reporting previously having had sex

\section{Substance use}

Of the 514 adolescents, $15.2 \%$ reported alcohol use, and $2.1 \%$ reported illicit drug use. In total, one-sixth reported at least one or the other (15.6\%). We were unable to assess substance use history on $8.6 \%$ of intake forms due to incomplete answers. Tobacco use, which was not considered "substance use" as per the WHO definition, was reported at 3.9\%. Among all patients, just under one-fifth reported having friends $(16.5 \%)$ or family $(19.3 \%)$ who engage in substance use. Those who reported illicit drug use either admitted to marijuana use, or failed to specify. Factors that significantly correlate with patient substance use (alcohol or drugs) include death of the mother $(p=0.041)$, presence of chronic illness $(p=0.038)$, a friend who uses one or more substances $(p<0.001)$, and a family member with a substance use problem $(p<0.001)$. See Table 2 and Figure 3.

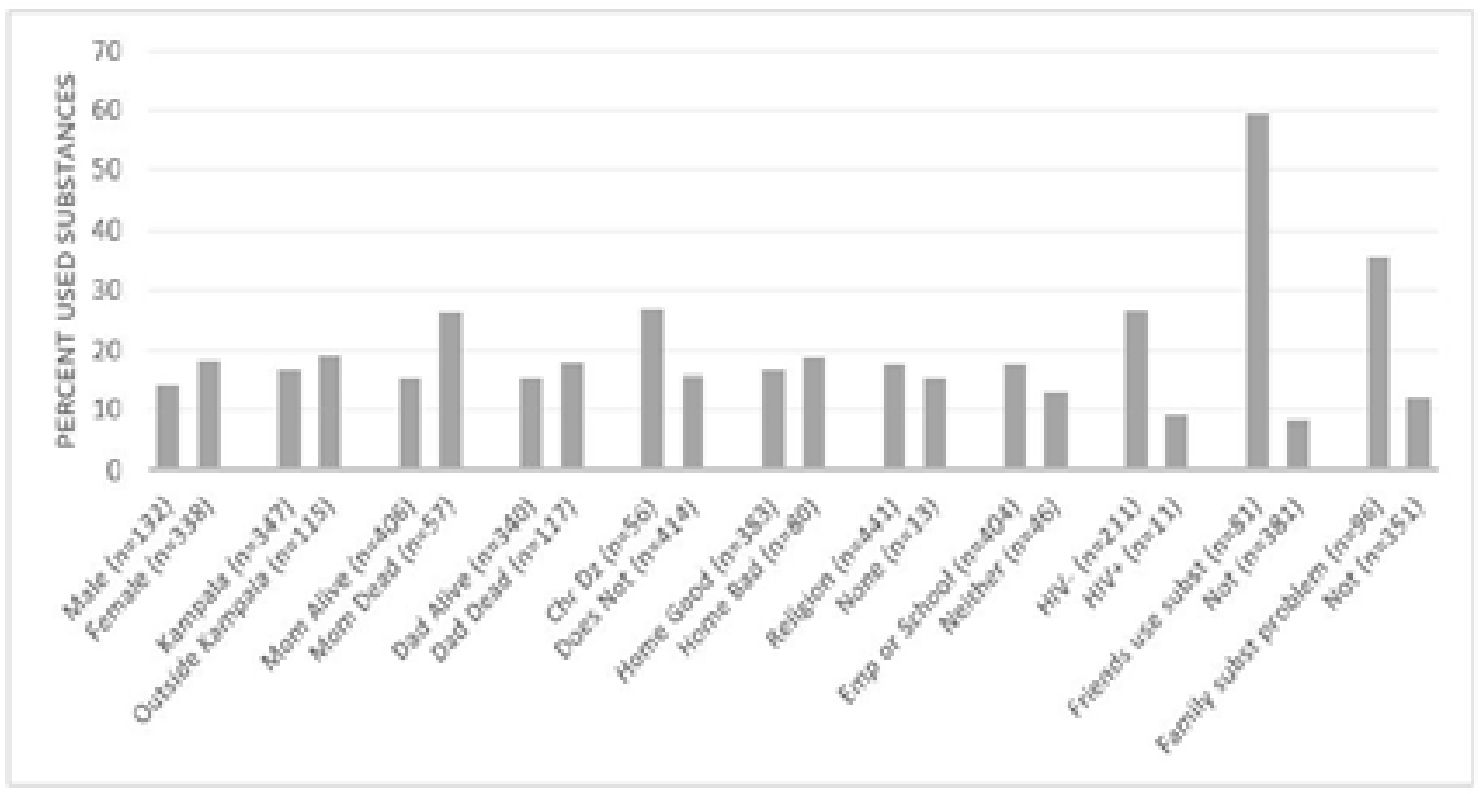

Figure 3: Percentage of Respondents Reporting Previous Use of Substances (either alcohol or illicit drugs) 


\section{Discussion}

This retrospective chart review has led to a better understanding of the needs of adolescents presenting for initial care at the Makerere/Mulago Columbia Adolescent Clinic (MMCAH) in Kampala, Uganda.

The self-reported presence of a chronic illness was significantly associated with depression, sexual activity, and substance use. The survey asked specifically about asthma, diabetes, cancer, sickle cell disease, HIV, epilepsy, tuberculosis, and sexually transmitted infections; responding "yes" to having one or more of these conditions was correlated with a history of depressive symptoms, sexual activity, or drug use $(p=0.026,0.006$, and 0.038 , respectively). This is consistent with several other studies. A study of adolescents aged 12-18 with sickle cell disease, asthma, or diabetes showed that they had increased rates of depression when compared to their peers ${ }^{15}$. More recently, a large meta-analysis by Pinquart and Shen including 33,047 adolescents and children with chronic illnesses (the most common being asthma, diabetes, cancer, chronic headache, and epilepsy) showed that the presence of one of these was associated with greater reporting of depressive symptomatology, and this trend was especially true among adolescents in developing countries. Between-group differences in that analysis were even more significant when depressive symptoms were reported by parents instead of adolescents, suggesting that the association may be even stronger than reported in our study, since all of our survey data were reported by the patients themselves. Absence of increased incidence of depressive symptoms among HIV-positive adolescents, noted both by us and Pinquart and Shen, could be explained by the fact that many of those infected at those young ages have not yet begun to experience symptoms of AIDS ${ }^{16}$. Adolescents with asthma have been found to be more likely to use tobacco or alcohol $1^{17,18,19}$ and be sexually active $^{17,19,20}$. Some studies suggest that those with chronic disease may participate less in sexual activity and substance use than their peers ${ }^{21,22}$, and other studies suggest no difference at all ${ }^{23,24}$. There is evidence that reported use of substances may be falsely low both in adolescents with and without chronic illness ${ }^{25}$, so further work must be done to understand the association specifically in the MMCAH population.

Presence of depressive symptoms was correlated with reported poor quality of home life. The impact of home life quality on depression $(p<0.001)$ was difficult to assess, however, as the intake form did not collect additional details. Past studies have shown associations between adolescent depression and poor economic status ${ }^{26}$, marital problems in the parents ${ }^{27}$, and abuse at home ${ }^{28}$, any of which could be related to our findings. More specific follow-up studies would need to be done to understand what is meant when adolescents reports poor quality of home life, and how that leads to depression. Depressive symptom history was not found to be correlated with gender, residence in Kampala versus outside the city, death of either parent, religious activity, being employed or in school, or HIV status.

The trend $(\mathrm{p}=0.063)$ found between female gender and depression is consistent with the significant association found in many other studies. Numerous studies have confirmed that adolescent females report depression and symptoms of depression at significantly higher rates than males ${ }^{29,30,31,32,33}$. Similar to our study, a study by Bennett et al. found no significant difference overall in prevalence of depressive symptoms by gender, but did find trends in the following: females were more likely to experience depressed mood and difficulty working, while males were more likely to experience morning fatigue and anhedonia $^{34}$. In a future study, changing the specific questions meant to assess depression could yield a different association between gender and depression, since males and females may experience different symptoms. While many factors are at play $^{32}$, differences between males and females seem to have much to do with different social roles and interpersonal stresses that girls and women cope with $^{29,33}$.

Poor quality of home life was also significantly associated with sexual activity $(\mathrm{p}=0.008)$. Lacking data on specific age of sexual debut but given that the mean age of the study population was only 16 years, we assumed that many patients reporting initiation of sexual activity may have had a debut before age 16, putting these young patients at higher risks of possible negative outcomes (pregnancy, sexually transmitted infections). We were unable to thoroughly assess the specific reasons behind reporting poor quality of home life and history of sexual activity due to lack of subsequent clarifying questions. However, we suspect that similar to other studies, early sexual debut could be related to poverty ${ }^{35}$ or a frequently absent 
father ${ }^{36}$, both of which could be possible reasons behind patients reporting poor home life quality. Future studies with more specific questioning are needed to clarify this issue.

Previous substance use (alcohol or drugs) was also associated with maternal death $(\mathrm{p}=0.041)$ and presence of friends or family members using substances $(\mathrm{p}<0.001$ in both cases). Few studies have explicitly examined the correlation between losing one or both parents and initiating substance use ${ }^{37}$. Among these studies, inconsistent correlations have been found. One study found a association between substance use and orphan status ${ }^{38}$, while another suggested that only paternal orphans are at increased risk of alcohol or drug use $\mathrm{e}^{37}$, and a third found findings similar to ours, that maternal orphans were at higher risk of drug use $^{39}$. This last study showed a strong correlation to drug use especially in males who lost their mothers, although it showed no correlation between orphan status and use of tobacco or alcohol ${ }^{39}$. On the other hand, the association between substance use in family and friends and personal initiation of use has long been strongly established ${ }^{40,41,42,43,44,45,46,47}$. While the influence of usage among peers and family is likely to do with increased acceptance and access to substances ${ }^{40}$, genetic factors may also contribute to substance use that "runs" in families ${ }^{48,49}$. This study is limited because analysis on use of both alcohol and drugs was done together in order to increase power; a larger group of adolescents or higher response rates on the intake form would be necessary to assess those using different substances separately.

\section{Limitations and future direction}

One major limitation of this study, in addition to those noted in the discussion above, is that it was a retrospective chart review with resultant missing files and unanswered questions within some files. These missing records limited the power of our analysis for certain associations. While it is unclear why certain records were missing, it is most likely related to lack of thorough interviews on busy clinic days, without a bias for which patients were and were not interviewed.

The intake form's primary purpose was to help guide the clinical interaction between physician and patient, and therefore answers to open-ended and dichotomous questions could be further elaborated on in that context (with details recorded in patient chart as opposed to the intake form). On the other hand, for research purposes, a challenge was coding open-ended questions into discrete categories, and having dichotomous questions that often were not expanded to include details that could have enriched our findings. The survey also often allowed for ambiguities, such as a precise definition of what "sex" means, that could be clarified clinically but not in a retrospective study. Additionally, certain questions on the intake for were good for guiding clinical interactions but imperfect proxies for the underlying conditions they are meant to measure (for example, the questions about depressive symptomatology are insufficient to diagnose a patient with depression for our analysis). A final issue with the intake form is that it was used to ask sensitive questions during the first interaction with the patient, and low levels of reporting (for example, substance use) compared to prior studies could result from these questions being asked early in the encounter by a new healthcare worker.

Since this study is a retrospective analysis, it is not possible to come to conclusions on causation. Depressive symptoms could arise from a poor home life, but a patient with depression could also be more likely to describe their quality of life at home as "poor". Likewise, being around friends who use substances may be a risk for substance use in a patient, or a patient who already uses substances could be drawn to others who do the same.

Future studies on factors associated with adolescent health outcomes could be strengthened by having a larger population for greater power. Additionally, restructuring of the intake form and providing an interviewer script could help guide a structured interview that provides valuable in-depth information for future analyses. Finally, future studies should assess the impact of information collected in the intake forms on planning of clinical interventions, and if those interventions are successful.

\section{Conclusion}

This study adds to the body of literature that focuses on factors influencing adolescent health outcomes; specifically, factors related to depressive symptoms, sexual activity, and substance use. This work was conducted in a location that has a region-specific dearth of the said literature: Kampala, Uganda. The results show that special attention should be paid to adolescents seen at the MMCAH with chronic illness, difficult home lives, de- 
ceased mothers, and substance-using family or friends, as all of these populations may be at higher risk of one or more negative health outcomes.

\section{Funders}

Funding for Michael Henry was provided by the MD/MS in Biomedical Sciences (Global Health Focus) funded by Columbia University IFAP Global Health Program.

\section{Acknowledgements}

Many thanks to the MMCAH staff, especially Kathy Lubowa, and to Professor Nancy Green for her advice and mentorship.

\section{Conflict of interest}

None declared.

\section{References}

1. Neema S, Ahmed F, Kibombo R, and Bankole A. Adolescent Sexual and Reproductive Health in Uganda Internet. New York: Guttmacher Institute; 2006 cited 29 Aug 2017. 150p. Available from https://www.guttmacher.org/ sites/default/files/pdfs/pubs/2006/08/14/or25.pdf

2. Abbo C, Okello E, Muhwezi W, Akello G, and Ovuga E. Alcohol, Substance Use and Psychosocial Competence in Selected Secondary Schools in Uganda: a cross sectional survey. International Neuropsychiatric Disease Journal. 2016; 7 (2): 25387.

3. Nalugya-Sserunjogi J, Rukundo G, Ovuga E, Kiwuwa S, Musisi S, and Nakimuli-Mpungu E. Prevalence and factors associated with depression symptoms among school-going adolescents in Central Uganda. Child and Adolescent Psychiatry and Mental Health. 2016; 10: 39.

4. Fact sheet: Adolescents: health risks and solutions Internet. Geneva: World Health Organization; 2016 cited 29 Aug 2017. Available from http://www.who.int/mediacentre/factsheets/fs345/en/

5. Dahl R. Adolescent Brain Development: A Period of Vulnerabilities and Opportunities (Keynote Address). Annals of the New York Academy of Sciences. 2004; 1021: 1-22.

6. Michaud P, Blum R, and Ferron C. "Bet you I will!" Risk or experimental behavior during adolescence? Archives of Pediatric and Adolescent Medicine. 1998; 152 (3): 224-226.

7. Stephens M. Preventive Health Counseling for Adolescents. American Family Physician. 2006; 74 (7): 1151-1156.

8. Ferrari A, Charlson F, Norman R, Patten S, Freedman G, Murray C, et al. Burden of Depressive Disorders by
Country, Sex, Age, and Year: Findings from the Global Burden of Disease Study 2010. PLos Medicine. 2013; 10 (11): e1001547.

9. Thapar A, Collishaw S, Pine D, and Thapar A. Depression in adolescence. Lancet. 2012; 379 (9820): 1056-1067. 10. Sedgh G, Finer L, Bankole A, Eilers M, and Singh S. Adolescent Pregnancy, Birth, and Abortion Rates Across Countries: Levels and Recent Trends. Journal of Adolescent Health. 2015; 56 (2): 223-230.

11. Cowan F and Pettifor A. HIV in adolescents in sub-Saharan Africa. Current Opinion in HIV and AIDS. 2009; 4 (4): 288-293.

12. Psychoactive Substance Use Among Adolescents Internet. Geneva: World Health Organization; 2009 cited 29 Aug 2017. Available from http://www.who.int/substance_abuse/activities/prevention_factsheets/en/

13. Newcomb M and Bentler P. Impact of adolescent drug use and social support on problems of young adults: A longitudinal study. Journal of Abnormal Psychology. 1988; 97 (1): 64-75.

14. Friday Adolescent Clinic on Ward 15, Makerere University, Department of Paediatrics, Mulago Hospital Internet. Kampala: Makerere/Mulago Columbia Adolescent Health Clinic; 2016 cited 29 Aug 2017. Available from http://www.sahu.ug/node/5

15. Seigel W, Golden N, Gough J, Lashley M, and Sacker I. Depression, self-esteem, and life events in adolescents with chronic diseases. Journal of Adolescent Health Care. 1990; 11 (6): 501-504.

16. Pinquart $M$ and Shen Y. Depressive Symptoms in Children and Adolescents with Chronic Physical Illness: An Updated Meta-Analysis. Journal of Pediatric Psychology. 2011; 36 (4): 375-384.

17. Suris J-C and Parera N. Sex, drugs and chronic illness: health behaviours among chronically ill youth. The European Journal of Public Health. 2005; 15 (5): 484-488.

18. Forero R, Bauman A, Young L, Booth M, and Nutbeam $\mathrm{D}$. Asthma,health behaviors, social adjustment, and psychosomatic symptoms in adolescence. Journal of Asthma. 1996; 33 (3): 157-164.

19. Suris J-C, Michaud P-A, Akre C, and Sawyer S. Health Risk Behaviors in Adolescents with Chronic Conditions. Pediatrics. 2008; 122 (5): 1113-1118.

20. Choquet M, Du Pasquier Fediaevsky L, and Manfredi R. Sexual behavior among adolescents reporting chronic conditions: a French national survey. Journal of Adolescent Health. 1997; 20 (1): 62-67.

21. Britto M, Garrett J, Dugliss M, Daeschner C, John- 
son C, Leigh M, Majure J, et al. Risky Behavior in Teens With Cystic Fibrosis or Sickle Cell Disease: A Multicenter Study. Pediatrics. 1998; 101 (2): 250-256.

22. Villarreal-Rodriguez D, Trevino-Garza C, Mancillas-Adame L, Martinez-Villarreal R, and de la O-Cavazos M. Adolescents with chronic disease and participation in risky behaviors. Medicina Universitaria. 2013; 15 (58): 2125.

23. Suris J-C, Resnick M, Cassuto N, and Blum R. Sexual behavior of adolescents with chronic disease and disability. Journal of Adolescent Health. 1996; 19 (2): 124-131.

24. Alderman E, Lauby J, and Coupey S. Problem behaviors in inner-city adolescents with chronic illnesses. Journal of Developmental and Behavioral Pediatrics. 1995; 16 (5): 339-344.

25. Masson E, MacFarlane I, Priestley C, Wallymahmed $\mathrm{M}$, and Flavell $\mathrm{H}$. Failure to prevent nicotine addiction in young people with diabetes. Archives of Disease in Childhood. 1992; 67: 100-102.

26. Tracy M, Zimmerman F, Galea S, McCauley E, and Vander Stoep A. What explains the relation between family poverty and childhood depressive symptoms? Journal of Psychiatric Research. 2008; 42 (14): 1163-1175.

27. Day R, Hair E, Moore K, Orthner D and Kaye K. Marital Quality and Outcomes for Children and Adolescents: A Review of the Family Process Literature Internet. Washington DC: Office of the Assistant Secretary for Planning and Evaluation, US Dept of Health and Human Services; 2009 cited 29 Aug 2017. 51 p. Available from https://aspe.hhs.gov/basic-report/marital-quality-and-outcomes-children-and-adolescents-review-family-process-literature

28. Moylan C, Herrenkohl T, Sousa C, Tajima E, Herrenkohl R, and Russo M. The Effects of Child Abuse and Exposure to Domestic Violence on Adolescent Internalizing and Externalizing Behavior Problems. Journal of Family Violence. 2010; 25 (1): 53-63.

29. Piccinelli $M$ and Wilkinson G. Gender differences in depression. The British Journal of Psychiatry. 2000; 177 (6): 486-492.

30. Nolen-Hoeksema S and Girgus J. The Emergence of Gender Differences in Depression During Adolescence. Psychological Bulletin 1994; 115 (3): 424-443. Journal of Studies on Alcobol. 1999; 13: 32-44.

44. Branstetter S, Low S, and Furman W. The influence of parents and friends on adolescent substance use: A multidimensional approach. Journal of Substance Use. 2011; 16 (2): 150-160.

45. Biederman J, Faraone S, Monuteaux M, and Feighner J. Patterns of alcohol and drug use in adolescents can be predicted by parental substance use disorders. Pediatrics. 2000; 106 (4): 792-797.

46. Yule A, Wilens T, Martelon M, Simon A, and Biederman J. Does exposure to parental substance use disorders increase substance use disorder risk in offspring? A 5-year follow-up study. American Journal of Addiction. 2013; 22 (5): 460-465.

47. Chassin L, Curran P, Hussong A, and Colder C. The Relation of Parent Alcoholism to Adolescent Substance Use: A Longitudinal Follow-Up Study. Journal of Abnormal Psychology. 1996; 105 (1): 70-80.

48. Lynskey M, Agrawal A, and Heath A. Genetically informative research on adolescent substance use: methods, findings and challenges. Journal of the American Academy of Child and Adolescent Psychiatry. 2010; 49 (12): 1202-1214. 49. Young S, Rhee S, Stallings M, Corley R, and Hewitt J. Genetic and environmental vulnerabilities underlying adolescent substance use and problem use: general or specific? Behavioral Genetics. 2006; 36 (4): 603-615. 